\title{
The study of separation of delapril's s-cis/s-trans isomers and development and validation of an analytical method for the estimation of delapril by reversed-phase liquid chromatography
}

\author{
Afef Ben Amar ${ }^{1, *}$, Mbarek Abidi², Najib Ben Hamida ${ }^{1}$ \\ ${ }^{1}$ Laboratoire de Chimie Analytique et Electrochimie, Département de Chimie, Faculté des Sciences de Tunis, \\ Campus Universitaire, 2092 EL Manar II, Tunis-Tunisie \\ ${ }^{2}$ Laboratoire National de Contrôle des Médicaments et de Dépistage du Dopage, 11 bis Rue Djebel Lakhdar, \\ 1006 Bab Saâdoun, Tunis-Tunisie
}

\begin{abstract}
Delapril is an angiotensin converting enzyme (ACE) inhibitor, which exists as a mixture of rotational s-trans and $s$-cis isomers due to the rotation of the amide bond. Although these stereoisomers do interconvert by rotation about the amide bond, the rate of interconversion is slow, allowing separation of the isomers on the chromatographic time scale. The effect of the flow-rate, column temperature, $\mathrm{pH}$, organic modifier, and counter-ion on the peak shape and the separation of the s-cis and s-trans conformers of delapril was investigated by HPLC. It was proved that the separation selectivity was improved by either a decrease of the flow-rate or an increase of the amount of the organic modifier or the addition of a positively charged counter ion. Delapril was then estimated by a reversed-phase liquid chromatographic method. This method was subsequently validated for specificity, linearity, accuracy and precision, according to the International Conference on Harmonization (ICH) guidelines. An NMR study indicates that the molecule exists as a mixture of rotational cis and trans isomers which confirms the results obtained by HPLC. The isomer ratio integrated from the obtained ${ }^{1} \mathrm{H}$ NMR result was 75:25 in DMSO-d ${ }^{6}$ at $298 \mathrm{~K}$, where the s-trans isomer was the major form.
\end{abstract}

Keywords: Delapril; conformer separation; HPLC; NMR; validation.

\section{Introduction}

Delapril, $N$-[N-(S)-1-ethoxycarbonyl-3-phenylpropyl]-(S)-alanyl- $N$-(indan-2-yl) glycine ${ }^{1}$, is a lipophilic nonsulfhydryl angiotensin-converting enzyme (ACE) inhibitor, which has been shown to exert potent ACE inhibitory activity ${ }^{2}$ and is marketed as an antihypertensive $\operatorname{drug}^{1}$.

Many analytical methods have been reported in the literature for the measurement of delapril in combination with manidipine in drug formulation such as liquid chromatographytandem mass spectrometry ${ }^{3}, \mathrm{RP}_{-} \mathrm{LC}^{4}$, UV spectrophotometry ${ }^{5}$ and micellar electrokinetic chromatography ${ }^{6}$. Moreover, $\mathrm{V}$. Todeschini and al. have reported on the characterization and evaluation of the drugs as raw materials ${ }^{7}$.

Delapril has been shown to exist in solution as a mixture of $s$-cis and s-trans conformational isomers (Figure 1), as a result of restricted rotation about the amide bond ${ }^{1}$. The rotational energy barrier is such that s-cis/s-trans interconversion happens at $320 \mathrm{~K}$ with 
$\Delta \mathrm{G}^{\#}=19.4 \mathrm{kcal} \mathrm{mol}^{-1}$, but the rotation around the peptide bond is restricted because of its partial double bond character ${ }^{1,8}$.

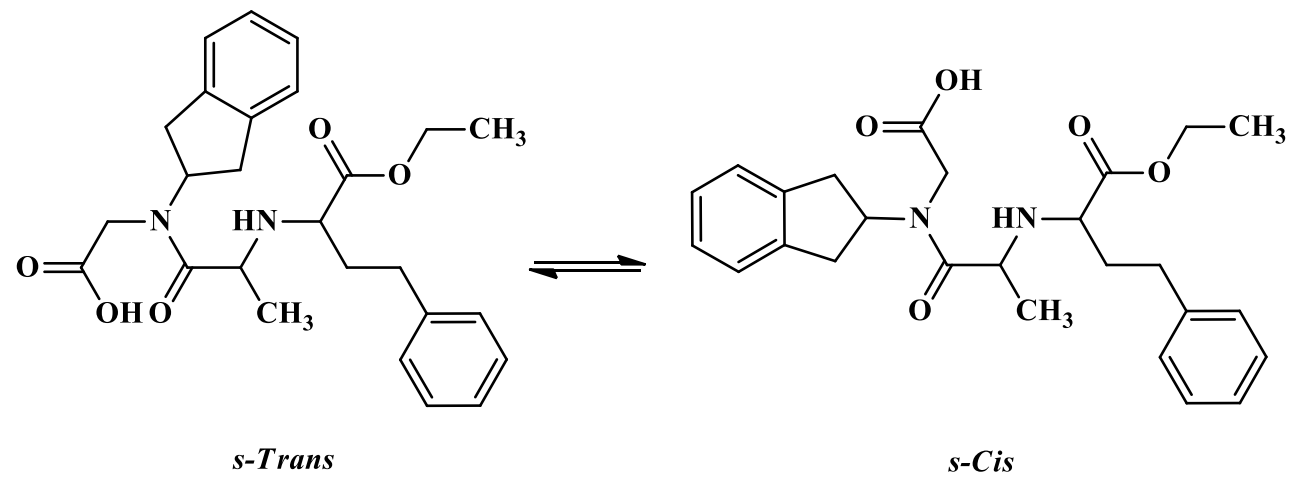

Figure 1. Chemical structure of the $s$-cis/s-trans forms of delapril

The conformational change yields elution profiles exhibiting peak-broadening, plateau formation, and coalescence ${ }^{9}$. We described in a recent paper ${ }^{10}$ that capillary zone electrophoresis (CZE) allows the study of the isomerization of delapril as a function of electrophoretic conditions. On the other hand, reversed-phase liquid chromatography has proven to be a meaningful tool for conformational and kinetic studies of similar products ${ }^{11-14}$.

In the present study, this technique is applied to the separation of delapril conformational isomers. The influence of the flow rate, temperature, $\mathrm{pH}$, organic modifier and counter-ions on the elution profiles of delapril was studied. A specific, accurate, precise and reproducible method, in which the drug elutes as a single peak, was then developed and validated. ${ }^{1} \mathrm{H}$ NMR spectroscopy was performed to prove the existence and elution order of the isomers and to define their ratio.

\section{Experimental Section}

\section{Chemicals and reagents}

All chemicals and reagents used in this study were of analytical grade. HPLC grade acetonitrile and water were obtained from Labscan (Dublin, Ireland), potassium dihydrogen phosphate, tetraethylammonium hydrogen sulphate and sodium pentanesulfonate were obtained from Fluka (Buchs, Switzerland), orthophosphoric acid (85\%) from Panreac (Barcelona, Espana), sodium hydroxide from Acros organics (Geel, Belgium) and sodium decanesulfonate from Applichem (Darmstadt, Germany). This study was conducted on a sample of delapril purchased from Sigma-Aldrich (St. Louis, MO, USA). Delapride tablets, containing $30 \mathrm{mg}$ delapril (DEL) and $2.5 \mathrm{mg}$ manidipine (MAN) per tablet, were obtained commercially. A fresh working solution was prepared daily. All solutions were filtered through a Cronus Nylon $0.45 \mu \mathrm{m}$ membrane filter and degassed using a Branson ultrasonic bath sonicator. Prior to the injection of the drug solution, the column was equilibrated by pumping the mobile phase flowing through the system for at least $30 \mathrm{~min}$.

\section{Instrumentation and chromatographic conditions}

The analysis of delapril was carried out on a Varian G 1600A HPLC system, equipped with a column oven $\left(25\right.$ to $90^{\circ} \mathrm{C}$ ) and a binary gradient pump (4 to 400 bar). Injection was performed using a manual injector with a loop injector with an injection capacity of $20 \mu \mathrm{L}$. 
The detector consisted of a diode array DAD UV-Visible detector (196 to $800 \mathrm{~nm}$ ). Separation was carried out on an Inertsil ODS-3 LC 18 column with $150 \times 4.6 \mathrm{~mm}$ I.D. and 5 $\mu \mathrm{m}$ particle size. Sample solution was injected into the column at a concentration of $200 \mu \mathrm{g}$ $\mathrm{mL}^{-1}$. Detection was performed at $\lambda=217 \mathrm{~nm}$. The work was carried out in an air conditioned room, maintained at a temperature of $25 \pm 2^{\circ} \mathrm{C}$. The $\mathrm{pH}$ of the mobile phase buffers was adjusted by means of a Metrohm model $744 \mathrm{pH}$ meter.

\section{Nuclear magnetic resonance NMR}

${ }^{1} \mathrm{H}$ NMR spectra was obtained at $300.13 \mathrm{MHz}$ on a Bruker AC 300 spectrometer. The probe temperature was $298 \mathrm{~K}$. ${ }^{1} \mathrm{H}$ chemicals shifts were measured relative to tetramethylsilane [TMS, $\left(\mathrm{CH}_{3}\right)_{4} \mathrm{Si}$ ]. The spectrum width was $4201.68 \mathrm{~Hz}$ and the relaxation time was $0.5 \mathrm{~s}$.

\section{Sample, standard and buffer solution preparations}

For analysis, $400 \mathrm{ppm}$ standard solution was prepared by dissolving $2 \mathrm{mg}$ of delapril in water, which was sonicated to dissolve the drug. Required concentrations were obtained from 400 ppm standard solution by proper dilution.

A buffer solution was prepared by dissolving an accurately weighed amount of $272.18 \mathrm{mg}$ of potassium dihydrogen phosphate in $100 \mathrm{~mL}$ of water, and the $\mathrm{pH}$ was adjusted with orthophosphoric acid, filtered through a Cronus Nylon $0.45 \mu \mathrm{m}$ membrane filter and degassed by sonication.

For NMR study, a sample solution was prepared by dissolving an appropriate amount of delapril in $1 \mathrm{~mL}$ of deuterated dimethyl sulphoxide $\left(\left[{ }^{2} \mathrm{H}_{6}\right]\right.$ DMSO) to obtain the desired concentration of delapril $\left(50 \mathrm{mg} \mathrm{mL}^{-1}\right)$. Also, an NMR experiment was carried out in $\mathrm{CD}_{3} \mathrm{CN} / \mathrm{D}_{2} \mathrm{O}(9 / 1, \mathrm{v} / \mathrm{v})$.

\section{Preparation of sample solutions}

The formulation tablets of DEL and MAN were crushed to give a finely powdered material. Tablet powder equivalent to $20 \mathrm{mg}$ of drug was accurately weighed, dissolved in $100 \mathrm{~mL}$ of water, sonicated for $5 \mathrm{~min}$ and filtered through a $0.45 \mu \mathrm{m}$ membrane filter.

\section{Results and Discussion}

\section{Flow-rate}

According to the column plate theory, the plate number is dependent on the flow rate of the mobile phase, and thus resolution is affected by the flow rate ${ }^{15}$. The influence of the flow-rate on the retention time and the peak shape of delapril was investigated at $25^{\circ} \mathrm{C}$ (Figure 2). The mobile phase was a mixture of acetonitrile and water $(90 / 10, v / v)$. It was found from the results that the flow rate had little effect on the selectivity $(\alpha)$ but it affected the resolution $\left(\mathrm{R}_{\mathrm{s}}\right)$ greatly, with a maximum at $0.5 \mathrm{~mL} \mathrm{~min}^{-1}$. Thus, clearly a better resolution was found at a flow-rate of $0.5 \mathrm{~mL} \mathrm{~min}^{-1}\left(\mathrm{R}_{\mathrm{s}}=1.41\right)$ vs $0.3 \mathrm{~mL} \mathrm{~min}^{-1}\left(\mathrm{R}_{\mathrm{s}}=0.83\right)$. At lower and medium flow rates, two distinct peaks corresponding to the two isomers were observed, indicating that isomerization occurs during chromatography. E. Redenti and al. have reported by singlecrystal X-ray structural analysis, that delapril exists in the trans form in the solid state ${ }^{1}$. It was shown that with elution at a slower flow-rate, the retention time should increase, and the probability that a molecule undergoes isomerization should increase ${ }^{16}$. However, at the higher flow-rate of $1.5 \mathrm{~mL} \mathrm{~min}^{-1}$, a single peak $\left(\mathrm{t}_{\mathrm{R}}=0.72 \mathrm{~min}\right)$ is obtained. 


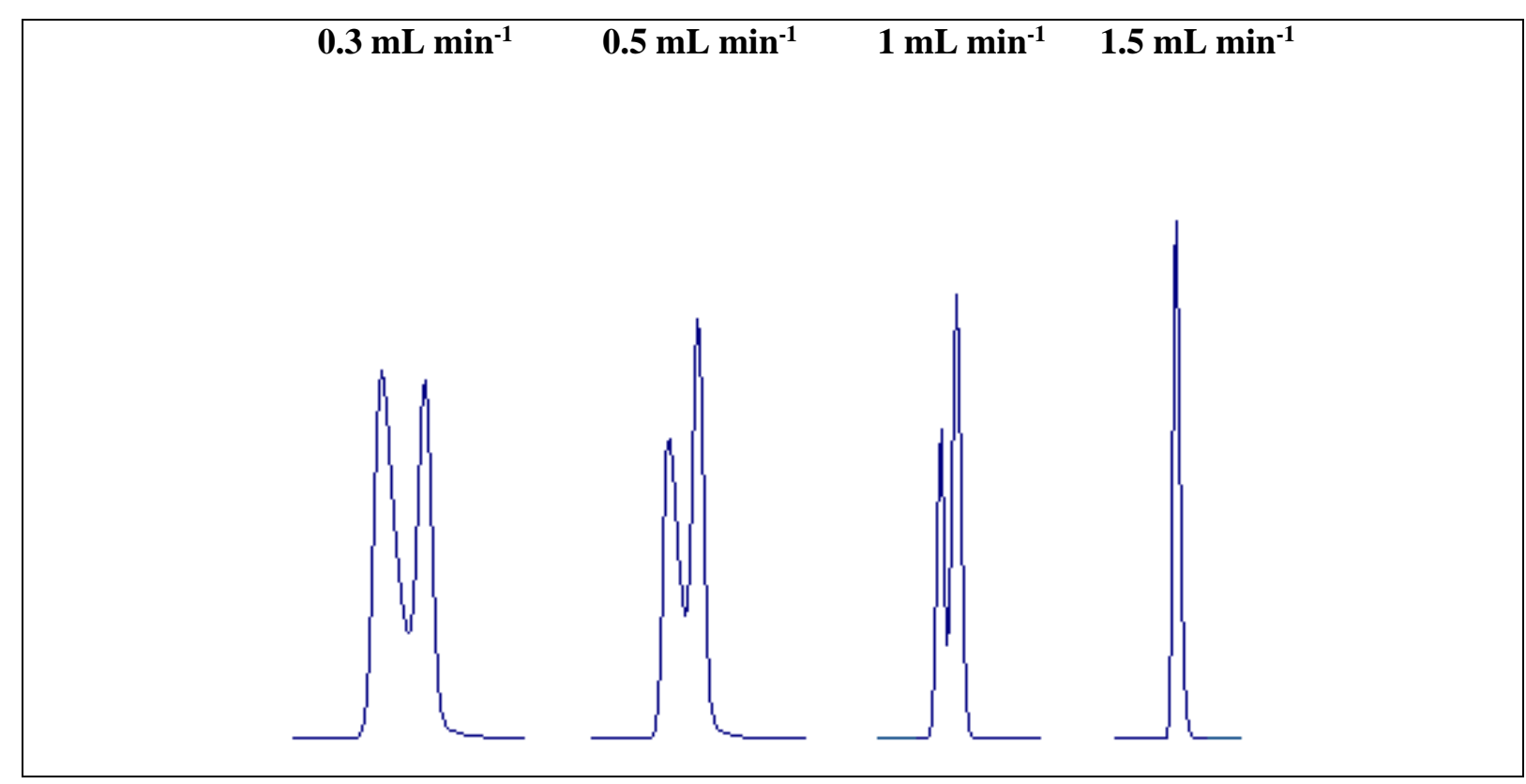

Figure 2. Effect of the flow rate on the retention time and peak shape of delapril: mobile phase: $(90 / 10, \mathrm{v} / \mathrm{v}) \mathrm{ACN} /$ water (neutral $\mathrm{pH}) ; \mathrm{T}=25^{\circ} \mathrm{C}$; Inertsil ODS-3 LC18 $5 \mu \mathrm{m}(150 \times 4.6 \mathrm{~mm}$ I.D. $)$

\section{Column temperature}

Temperature has been found to be the most important operational variable to affect the efficiency of separation of interconverting species in HPLC ${ }^{17}$. Chromatograms of delapril obtained at several column temperatures, with a mobile phase containing $90 \%$ acetonitrile at a flow rate of $0.5 \mathrm{~mL} \mathrm{~min}^{-1}$, are shown in Figure 3. Elevated temperatures led to a deterioration of separation of the two conformers. Moreover, resolution between the s-cis/s-trans isomers is lost. This has been attributed earlier to the kinetic effects of the isomerization where the rate of rotation about the amide bond is faster than the chromatographic time scale which results in a single peak at $55^{\circ} \mathrm{C}$. It was shown that raising the temperature of the chromatographic column markedly hastened the interconversion of these two components and destroyed their baseline resolution ${ }^{18}$. Insofar as the influence of conformational change on peak shape is governed by the rate of isomerization which increases with temperature with respect to the time scale of HPLC elution, higher isomerization rates would most likely result in a single peak. On the other hand, at low temperature $\left(20^{\circ} \mathrm{C}\right)$ the two isomers were resolved almost completely indicating that the inter-conversion rate was slowed down. A better resolution was found at a temperature of $20^{\circ} \mathrm{C}\left(\mathrm{R}_{\mathrm{s}}=2.34\right)$ vs $25^{\circ} \mathrm{C}\left(\mathrm{R}_{\mathrm{s}}=1.42\right)$. By decreasing the temperature, the interconversion is slow compared to the separation process, in this case two distinct peaks are observed for the two conformers. It was reported that subambient-temperature chromatography can be used to study interconverting isomers with low interconversion barriers ${ }^{19}$. However, the effect of temperature on retention is less significant. The same results were obtained in a previous RPLC studies on similar products ${ }^{13,20-24}$. From an ambient temperature chromatogram the isomer ratio was integrated to be 70:30.

However, the separation of the two conformers suggests that their hydrophobic surface areas are different as it can be seen from the molecular structures of cis and trans delapril in Figure 1. Indeed, the trans form has a lower hydrophobic surface area than the cis form, where its polar and non-polar groups are separated with respect to the plane through the two $\alpha$ carbons. Thus, the trans conformer binds less strongly to the hydrocarbonaceous ligates of the 
stationary phase than the cis conformer and therefore it can be expected that the retention of the cis form is greater than the one of the trans isomer. This is argued in earlier studies on the separation of enalaprilat isomers ${ }^{22}$.

Moreover, a decrease in the temperature is expected to lead to a displacement of the conformational equilibrium in favor of the s-trans conformer ${ }^{24}$. The latter is stabilized by hydrogen bonding between the carbonyl group of the amide function and the hydrogen of hydroxyl group of the acid function.

Therefore, as the temperature increases, the relative proportion of the s-trans isomer decreases due to the loosening of intramolecular hydrogen bond. Thus, the first eluted peak in the RPLC chromatogram corresponds most likely to the s-trans conformer.

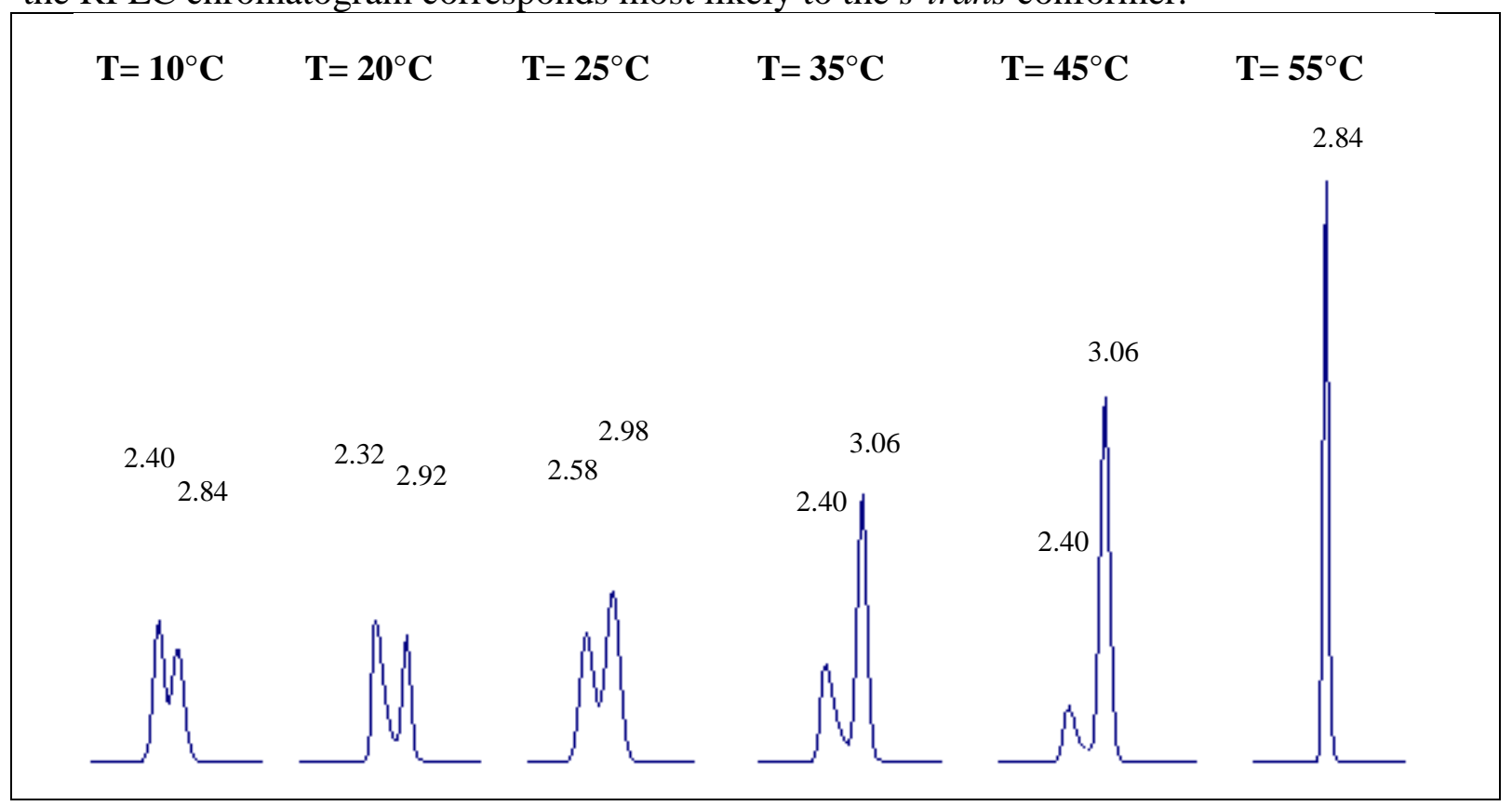

Figure 3. Effect of column temperature on the peak shape of delapril: mobile phase: $(90 / 10$, v/v) ACN/water (neutral pH); $0.5 \mathrm{~mL} \mathrm{~min}^{-1}$; Inertsil ODS-3 LC18 $5 \mu \mathrm{m}$ (150×4.6 mm I.D.)

\section{Effect of organic modifier}

It is known that the isomeric equilibrium and the rate of isomerisation are strongly influenced by organic modifier content ${ }^{25}$. To investigate the effect of the amount of the organic modifier, various concentrations of acetonitrile were used at $25^{\circ} \mathrm{C}$ at a flow rate of 1 $\mathrm{mL} \min ^{-1}$. The chromatograms obtained are depicted in Figure 4. A high concentration (90\%) of acetonitrile favors a good separation of the two isomers. As shown, the peak split is observed only at a higher percentage of organic modifier ${ }^{26}$. On the other hand, as could be expected in reversed phase systems, an increase in the organic modifier concentration resulted in a decrease in retention time. The decrease in polarity of the mobile phase, as the acetonitrile content increases, results in the preferential partitioning of the drug in the mobile phase as compared to a mobile phase composition with lower amounts of organic modifier, favoring elution of the molecule. It was found from the results that going from lower concentrations to higher concentrations of acetonitrile, the retention time decreases. However, a decrease in the amount of organic modifier yielded a single peak. 


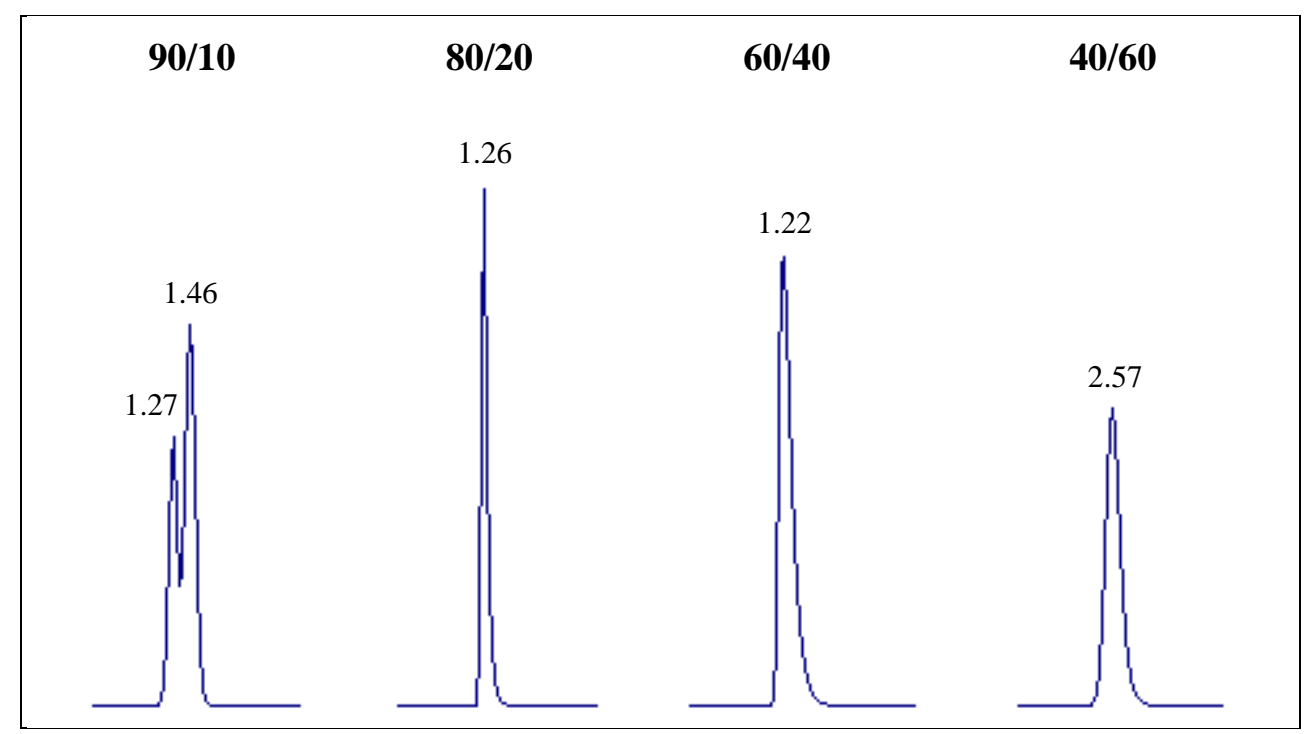

Figure 4. Effect of organic modifier on the peak shape and retention time of delapril: mobile phase: (v/v) ACN/water; $\mathrm{T}=25^{\circ} \mathrm{C} ; 1 \mathrm{~mL} \mathrm{~min}^{-1}$; Inertsil ODS-3 LC18 $5 \mu \mathrm{m}$ (150×4.6 mm I.D.)

\section{Effect of $\mathbf{p H}$}

The chromatographic behavior of delapril obtained at different $\mathrm{pHs}$ in the range 3-7, using a mobile phase consisting of $20 \mathrm{mM}$ phosphate buffer-acetonitrile $(10 / 90, \mathrm{v} / \mathrm{v})$ at $25^{\circ} \mathrm{C}$ and a flow rate of $2 \mathrm{~mL} \mathrm{~min}{ }^{-1}$, is shown in Figure 5. Retention was found to increase with decreasing $\mathrm{pH}$ as reported earlier for similar products. This suggests that interaction occurs between unreacted silanols and molecules which are positively charged at low $\mathrm{pH}$ giving rise to an increase in their retention times ${ }^{14,21,27-28}$. This interaction phenomenon appears to be predominant in the retention time of similar analytes ${ }^{29}$. It was reported that silanophilic interactions, which may interfere in the retention mechanism, depend on the presence of functional groups in the solute molecules ${ }^{26}$. Delapril has an indane group in its molecule that differentiates it from perindopril which has a perhydroindole group.

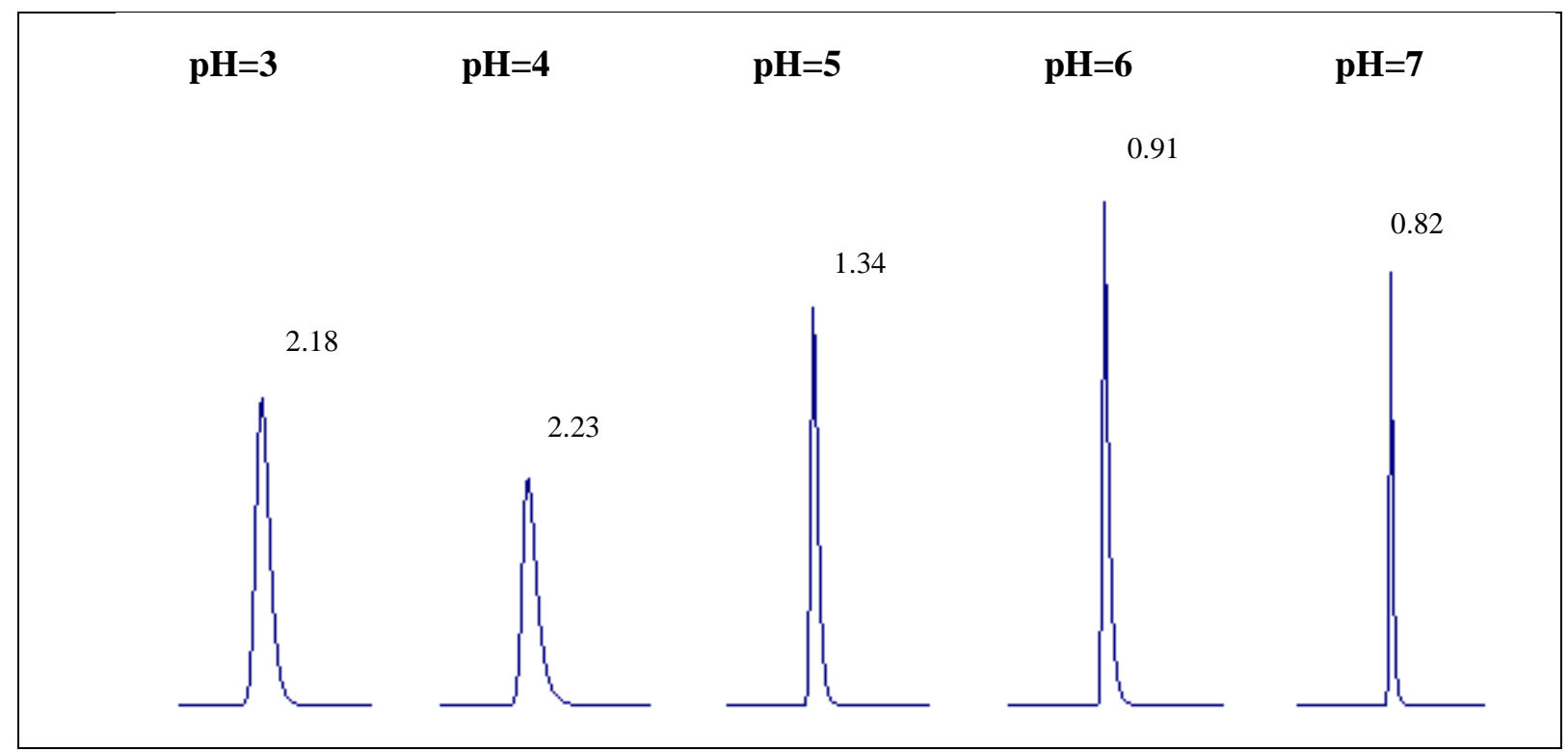

Figure 5. Effect of buffer $\mathrm{pH}$ on retention time of delapril: mobile phase: (90/10, v/v) ACN/ phosphate buffer $(20 \mathrm{mM}) ; 2 \mathrm{~mL} \mathrm{~min}^{-1} ; \mathrm{T}=25^{\circ} \mathrm{C}$; Inertsil ODS-3 LC18 $5 \mu \mathrm{m}(150 \times 4.6 \mathrm{~mm}$ I.D. $)$ 
Moreover, perindopril does not contain an aromatic phenyl group as delapril does. However, the $\mathrm{pH}$ of mobile phase does not affect the peak shape of delapril. It is worth noting that the results show that the separation of the two conformers deteriorated, even with a decreasing flow-rate, with the use of phosphate-buffer, and that the use of the phosphate buffer has an insignificant effect on the peak shape of delapril.

\section{Influence of counter-ion}

Sodium pentanesulfonate (NaPS), sodium decanesulfonate (NaDS) and tetraethyl ammonium hydrogensulfate (HTEA) were used as ionic modifiers at various concentrations. They were separately added to the mobile phases containing $20 \mathrm{mM}$ phosphate bufferacetonitrile $(10 / 90, \mathrm{v} / \mathrm{v})$ at $25^{\circ} \mathrm{C}$. Since the pka values of delapril are 3.26 (the carboxyl group) and 5.65 (the amine group) ${ }^{30}$ the apparent $\mathrm{pH}$ of the mobile phases was adjusted to 7 and 3 for experiments with HTEA (positive counter-ion) and NaDS and NaPS (negative counter-ion) respectively. As shown in Figures 7, 8 and 9, at lower HTEA concentration, an increase of the retention time was observed with a significant improvement of rotamer separation, whereas at higher HTEA concentration (100 ppm), a single peak was obtained. Nevertheless, the use of $\mathrm{NaPS}$ and NaDS resulted in an insignificant decrease of retention time and elution of delapril as a single peak.

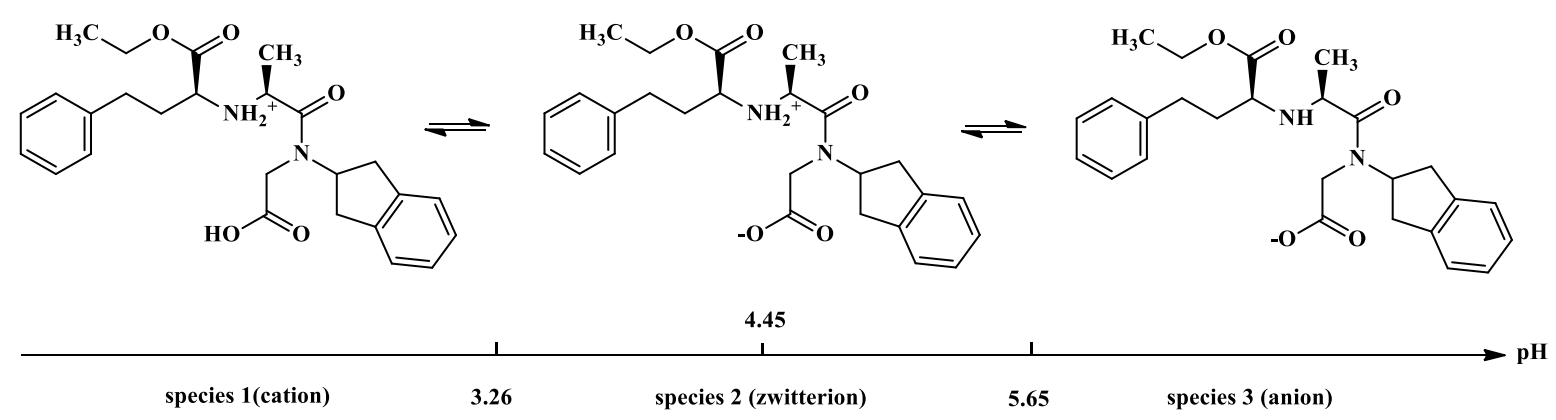

Figure 6. Different species of delapril as a function of $\mathrm{pH}$

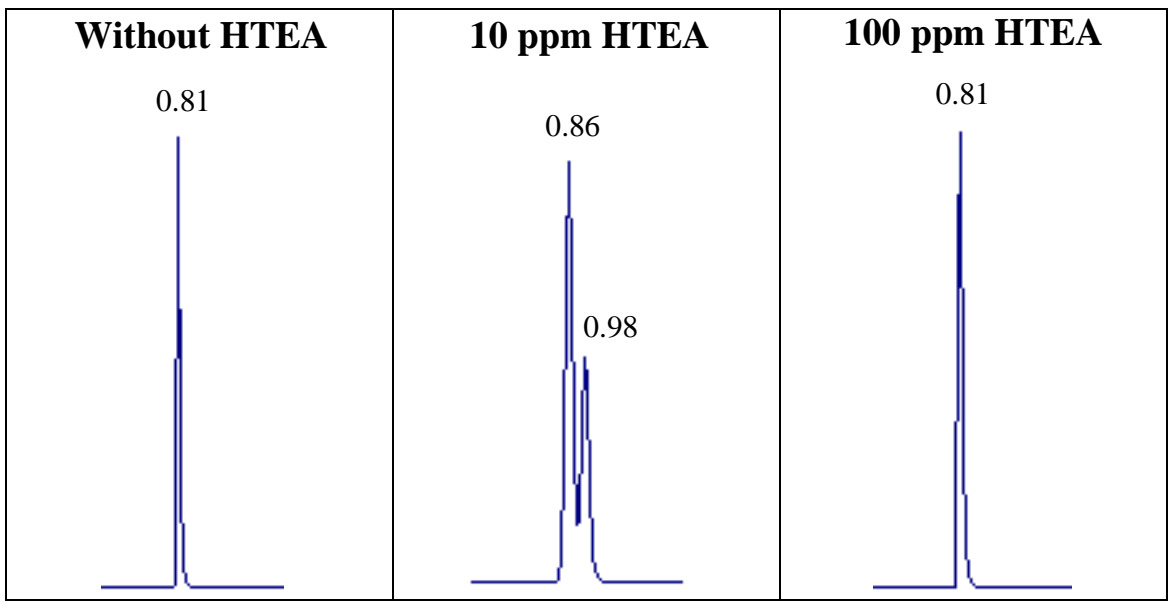

Figure 7. Effect of HTEA on the retention time and peak shape of delapril: mobile phase: (90/10, v/v) ACN/ phosphate buffer $(20 \mathrm{mM} ; \mathrm{pH}=7) ; 2 \mathrm{~mL} \mathrm{~min}^{-1} ; \mathrm{T}=25^{\circ} \mathrm{C}$; Inertsil ODS-3 LC18 $5 \mu \mathrm{m}(150 \times 4.6 \mathrm{~mm}$ I.D. $)$ 


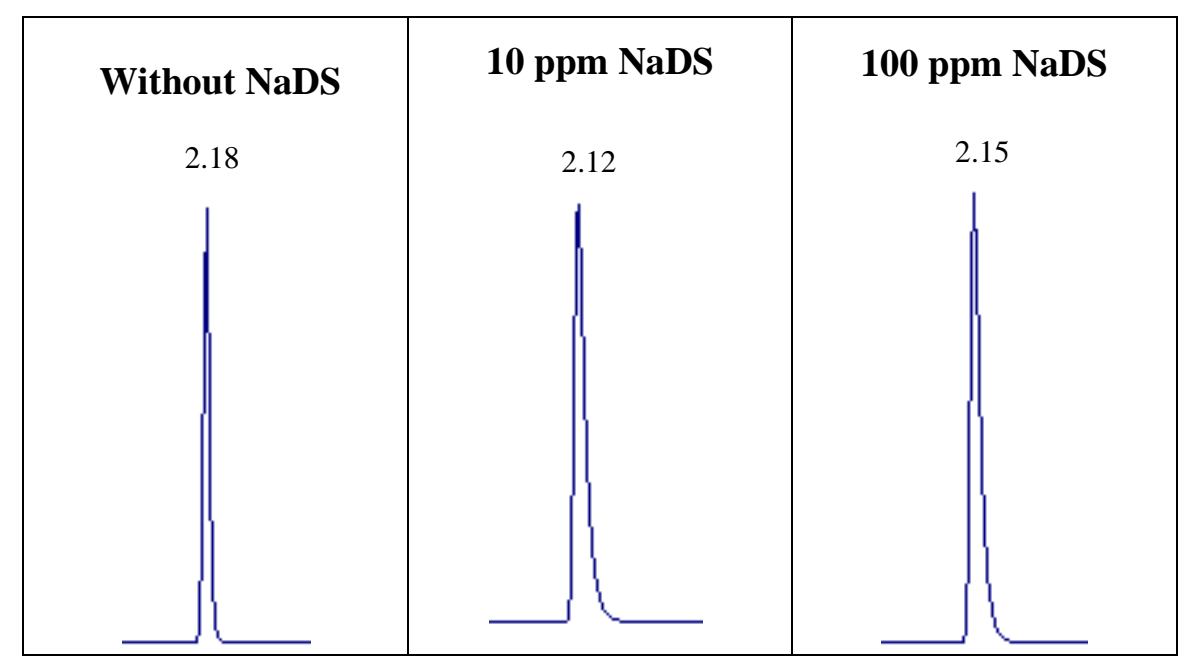

Figure 8. Effect of NaDS on the retention time of delapril: mobile phase: $(90 / 10, \mathrm{v} / \mathrm{v}) \mathrm{ACN} /$ phosphate buffer $(20 \mathrm{mM} ; \mathrm{pH}=3) ; 2 \mathrm{~mL} \mathrm{~min}^{-1} ; \mathrm{T}=25^{\circ} \mathrm{C}$; Inertsil ODS-3 LC18 $5 \mu \mathrm{m}(150 \times 4.6 \mathrm{~mm}$ I.D. $)$

\begin{tabular}{|c|c|c|}
\hline Without NaPS & 10 ppm NaPS & 100 ppm NaPS \\
2.18 & 2.07 & 2.12 \\
& & \\
\hline
\end{tabular}

Figure 9. Effect of NaPS on the retention time of delapril: mobile phase: $(90 / 10, \mathrm{v} / \mathrm{v}) \mathrm{ACN} /$ phosphate buffer $(20 \mathrm{mM} ; \mathrm{pH}=3) ; 2 \mathrm{~mL} \mathrm{~min}^{-1} ; \mathrm{T}=25^{\circ} \mathrm{C}$;

Inertsil ODS-3 LC18 $5 \mu \mathrm{m}(150 \times 4.6 \mathrm{~mm}$ I.D. $)$

\section{Method development for the determination of delapril}

An analytical method was developed for the estimation of the drug by reversed-phase liquid chromatography. A series of parameters, consisting of composition and $\mathrm{pH}$ of mobile phase, flow rate, buffer molarity and counter-ion, were tested with respect to the retention and shape of the delapril peak in the corresponding chromatograms. As the final optimized method, a mobile phase consisting of potassium dihydrogen phosphate buffer $(20 \mathrm{mM}$; $\mathrm{pH}=$ 2.5) and acetonitrile in the ratio of $30: 70 \mathrm{v} / \mathrm{v}$ was delivered at a flow rate of $1 \mathrm{~mL} \mathrm{~min}^{-1}$. Chromatography was performed on an Inertsil ODS-3 LC 18 column (150 mm; $4.6 \mathrm{~mm}$ I.D.; $5 \mu \mathrm{m})$ maintained at temperature of $25^{\circ} \mathrm{C}$. The detection wavelength was $217 \mathrm{~nm}$. The retention time for delapril was $2.96 \mathrm{~min}$. 


\section{Method validation}

Introduction

The United States Pharmacopeia (USP) ${ }^{31}$ states that the validation of an analytical method is a process that establishes the performance characteristics of a developed analytical method and ensures that it meets its intended purpose and analytical application. Method validation includes an assessment of the adequacy of the analytical procedure by means of statistical testing, including linear regression analysis, and relative standard deviation determination in order to demonstrate the validity of the method ${ }^{32}$.

The International Conference on Harmonisation of Technical Requirements for Registration of Pharmaceuticals for Human Use $(\mathrm{ICH})^{33}$ recognizes accuracy, precision, repeatability, intermediate precision, specificity, limits of quantification and detection, linearity, and the range of a method as important validation parameters.

\section{Specificity}

Specificity is the ability to assess unequivocally the analyte in the presence of components which may be expected to be present. Typically these might include impurities, degradants, matrix, etc ${ }^{33}$.

The excipients in the tablets used in this study contained the following inactive ingredients: lactose, low-substituted hydroxypropylcellulose, hydroxypropylcellulose and magnesium stearate as excipients. The specificity of the method was assessed by comparing the chromatograms obtained from drug standard and from placebo solution prepared from the excipients. No excipient peaks co-eluted with the analyte, indicating that the method is selective and specific in relation to the excipients used in this study (Figure 10).
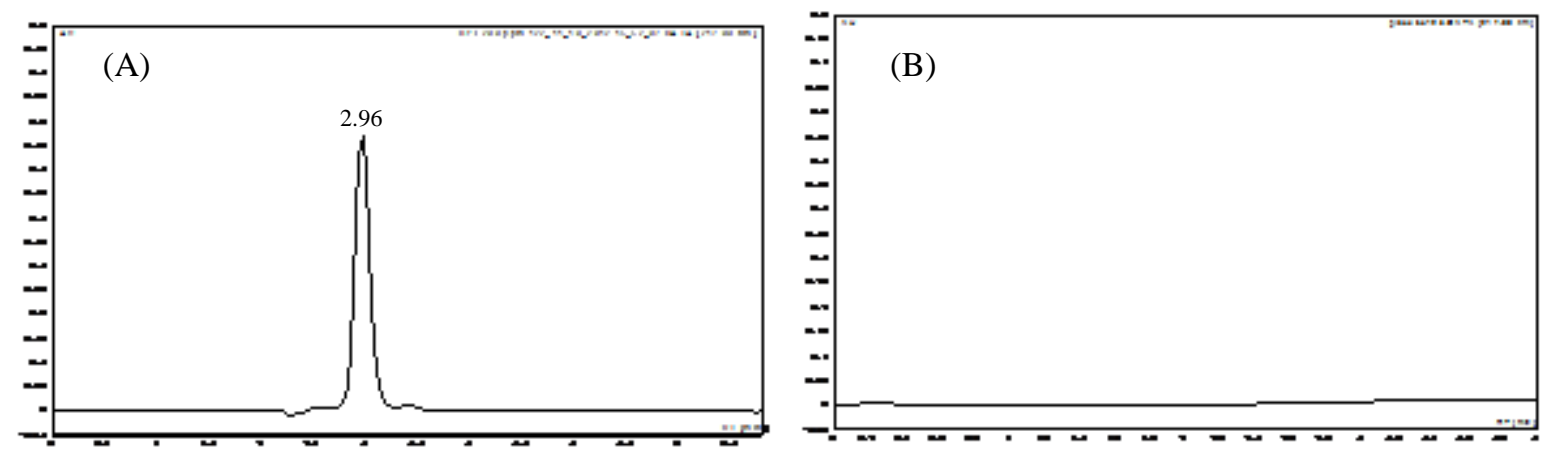

Figure 10. Chromatograms obtained from (A) a drug standard and (B) a placebo solution: mobile phase: $(70 / 30 \mathrm{v} / \mathrm{v}) \mathrm{ACN} /$ phosphate buffer $(20 \mathrm{mM}, \mathrm{pH}=2.5) ; 1 \mathrm{~mL} \mathrm{~min}^{-1} ; \mathrm{T}=25^{\circ} \mathrm{C}$; Inertsil LC18 $5 \mu \mathrm{m}(150 \times 4.6 \mathrm{~mm}$ I.D. $)$

\section{Linearity}

The linearity of an analytical procedure is its ability (within a given range) to obtain test results which are directly proportional to the concentration (amount) of analyte in the sample ${ }^{33}$.

Linearity of the proposed method was investigated by analyzing five dilutions for delapril in the range of $120-280 \mathrm{ug} \mathrm{mL} \mathrm{m}^{-1}$. This concentration range corresponds to the levels of 60 $140 \% \mathrm{w} / \mathrm{w}$ of the nominal analytical concentration. Twenty microliters of each concentration was injected in triplicate into the HPLC system on three days.

The calibration curve for delapril (Figure 11) was obtained by plotting the peak area ratio versus the concentration of delapril over the range of 120-280 ppm. The regression equation of DEL concentration over its peak area ratio was found to be $y=0.0291 \mathrm{x}+0.0226$, where $\mathrm{x}$ 
is the concentration of delapril (ppm) and y is the respective peak area. The calibration curve showed excellent linearity, over the calibration range studied, with a coefficient of determination $\mathrm{R}^{2}>0.995$ which apparent a linear affiliation between concentration and peak area. The data of regression analysis of the calibration curve is shown in Table 1.

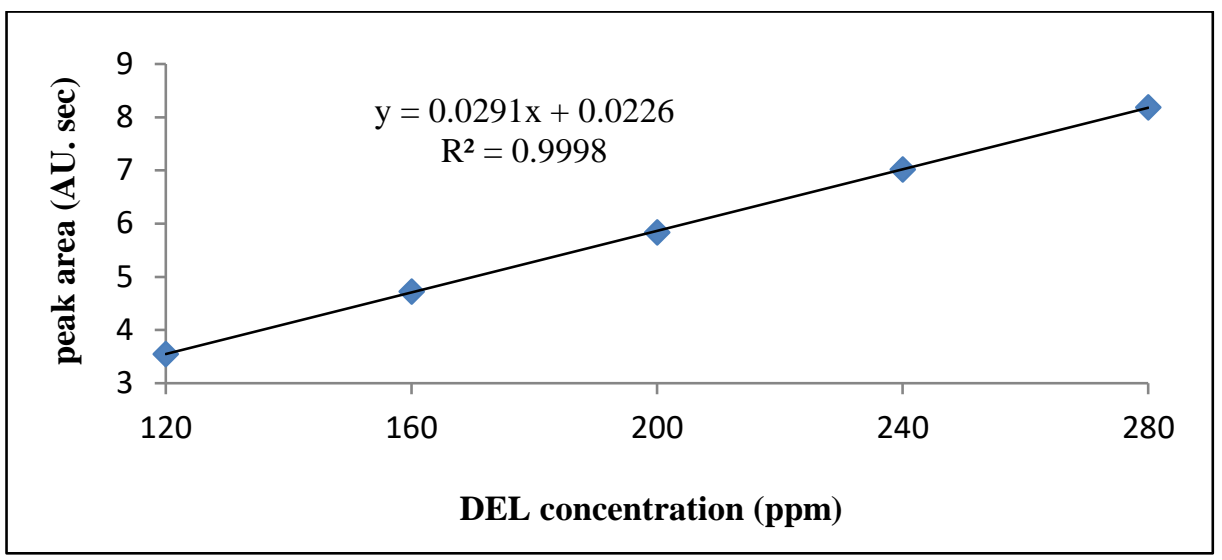

Figure 11. Calibration curve for delapril

Table 1. Regression analysis of the calibration curve.

\begin{tabular}{|c|c|}
\hline Parameters & Values \\
\hline Calibration range $(\mathrm{ppm})$ & $120-280$ \\
\hline Slope & 0.0291 \\
\hline Intercept & 0.0226 \\
\hline Correlation coefficient $\left(\mathrm{R}^{2}\right)$ & 0.9998 \\
\hline
\end{tabular}

Table 2. Accuracy parameters.

\begin{tabular}{|c|c|c|c|}
\hline Level & $\begin{array}{c}\text { Theoretical } \\
\text { concentration } \\
\left(\mu \mathrm{g} \mathrm{mL}^{-1}\right)\end{array}$ & $\begin{array}{c}\text { Resultant } \\
\text { concentration } \\
\left(\mu \mathrm{g} \mathrm{mL}^{-1}\right)\end{array}$ & Recovery (\%) \\
\hline \multirow{3}{*}{$60 \%$} & 120 & 120.0914 & 100.0762 \\
\hline & 120 & 121.4603 & 101.2169 \\
\hline & 120 & 118.2917 & 98.5765 \\
\hline \multirow{3}{*}{$80 \%$} & 160 & 160.5972 & 100.3733 \\
\hline & 160 & 158.9888 & 99.3680 \\
\hline & 160 & 162.2979 & 101.4362 \\
\hline \multirow{3}{*}{$100 \%$} & 200 & 199.3391 & 99.6696 \\
\hline & 200 & 198.8634 & 99.4317 \\
\hline & 200 & 199.2561 & 99.6281 \\
\hline \multirow{3}{*}{$120 \%$} & 240 & 239.1644 & 99.6518 \\
\hline & 240 & 239.4657 & 99.7774 \\
\hline & 240 & 241.4272 & 100.5947 \\
\hline \multirow{3}{*}{$140 \%$} & 280 & 280.8078 & 100.2885 \\
\hline & 280 & 281.2218 & 100.4364 \\
\hline & 280 & 278.7271 & 99.5454 \\
\hline \multicolumn{4}{|c|}{ Mean recovery $(\%)=100.005 \pm 0.410$} \\
\hline
\end{tabular}




\section{Accuracy}

The accuracy of an analytical procedure expresses the closeness of agreement between the value which is accepted either as a conventional true value or an accepted reference value and the value found ${ }^{33}$.

The accuracy of the method was evaluated by determination of the recovery of delapril on three days at five levels concentration in the range of $120-280 \mathrm{ppm}$ corresponding to the levels of $60 \%$ to $140 \%$ of the nominal analytical concentration. The results showed good recoveries ranging from $98.5765 \%$ to $101.4362 \%$ for delapril. The resultant concentration was determined by interpolation of the data from the calibration curve. The mean recovery data obtained for each level as well as for all levels combined were within $2 \%$ of the label claim for the active substance an R.S.D. < $2 \%$, which satisfied the acceptance criteria set for the study (Table 2).

The intra-day precision study of delapril was carried out by estimating the correspondence responses six times on the same day with $200 \mathrm{ppm}$ concentration and inter-day precision study of delapril was carried out by estimating the correspondence responses six times on the next day with 200 ppm concentration.

The precision articulated as inter and intra-day \% RSD <2, which indicates that there was no significant difference for the assay which was tested within one day and between days (Table 3).

Table 3. Inter-day and intra-day precision data.

\begin{tabular}{|l|c|c|}
\hline days & $\mathrm{k}$ & 3 \\
\hline assays & $\mathrm{N}$ & 6 \\
\hline variance of repeatability & $\mathrm{s}^{2}{ }_{\mathrm{r}}$ & 2.6518 \\
\hline Variance of intermediate precision & $\mathrm{s}^{2}{ }_{\mathrm{R}}$ & 2.2791 \\
\hline Mean recovery (\%) & $\mathrm{M}$ & 99.3449 \\
\hline$\%$ RSD of repeatability & $100^{*} \mathrm{~s}_{\mathrm{r}} / \mathrm{m}$ & $\mathbf{1 . 6 3 9 2}$ \\
\hline$\%$ RSD of intermediate precision & $100 * \mathrm{~s}_{\mathrm{R}} / \mathrm{m}$ & $\mathbf{1 . 5 1 9 6}$ \\
\hline
\end{tabular}

\section{Detection limit and Quantification limit}

The detection limit of an individual analytical procedure is the lowest amount of analyte in a sample which can be detected but not necessarily quantified as an exact value ${ }^{33}$.

The quantification limit of an individual analytical procedure is the lowest amount of analyte in a sample which can be quantitatively determined with suitable precision and accuracy. The quantification limit is a parameter of quantitative assays for low levels of compounds in sample matrices, and is used particularly for the determination of impurities and/or degradation products ${ }^{33}$.

The analytical sensitivity of the method was anticipated from the signal to noise ratio 3:1 and 10:1. The minimum limits at which the analytes can be readily detected (LOD) and quantified (LOQ) for delapril were 0.02 and $0.066 \mu \mathrm{g} \mathrm{mL}^{-1}$ respectively.

\section{Tablet study}

The proposed method was successfully applied to the analysis of marketed product (Delapride ${ }^{\circledR}$ ) with a recovery of $98 \%$. 


\section{NMR study}

The ${ }^{1} \mathrm{H}$ NMR spectrum of delapril is shown in Figure 12. In the chemical shift range 1-1.6 ppm the spectrum exhibits two distinct sets of signals of unequal intensities for each of the two methyl groups present in the molecule, which reveals the existence of two contributing conformers. These rotamers are assigned to the s-cis/s-trans equilibrium of the rotation around the amide bond. The rotamer ratio in DMSO was integrated to be 75:25 at $298 \mathrm{~K}$. A similar result was obtained in a previous NMR study of delapril hydrochloride ${ }^{1}$. We conclude that the major conformer in the ${ }^{1} \mathrm{H}$ NMR spectrum of delapril likely corresponds to the first eluted peak in the RPLC chromatogram, which exists in a higher proportion. A similar study demonstrated this correspondence in the case of ramiprilat ${ }^{15}$, enalaprilat ${ }^{22}$, and lisinopril ${ }^{24}$ in different solvents.

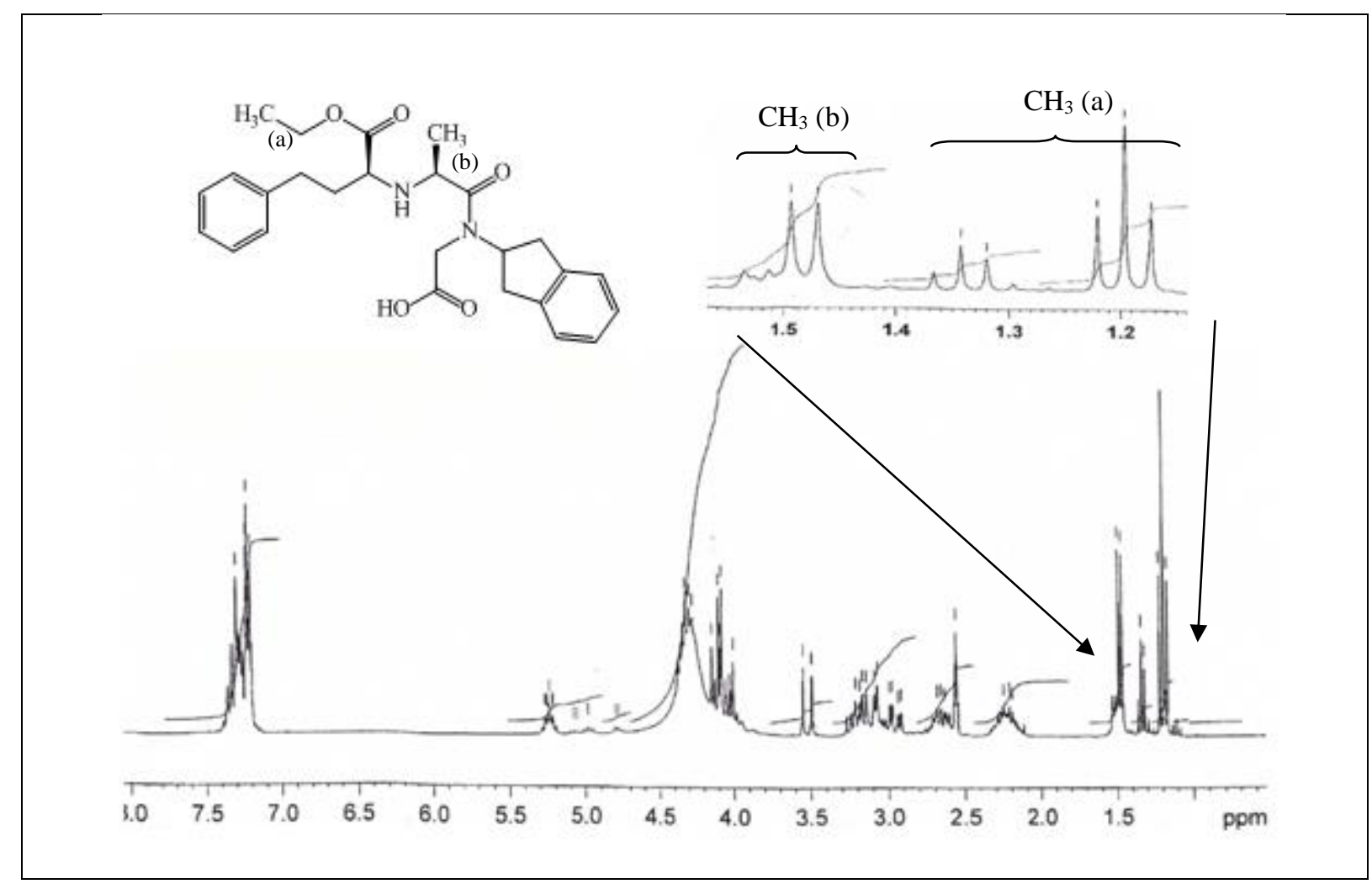

Figure 12. ${ }^{1} \mathrm{H}$ NMR spectrum of delapril in DMSO at $298 \mathrm{~K}$

Another ${ }^{1} \mathrm{H}$ NMR spectrum of delapril was recorded in $\mathrm{CD}_{3} \mathrm{CN} / \mathrm{D}_{2} \mathrm{O}(9 / 1$, v/v) at $298 \mathrm{~K}$ (Figure 13). Again, in the chemical shift range 1.1-1.8 ppm the spectrum exhibits two distinct sets of signals of unequal intensities for each of the methyl groups, which indicates the existence of the two isomers. The isomer ratio was integrated to be 71/29. Again, we conclude that the major conformer in the ${ }^{1} \mathrm{H}$ NMR spectrum of delapril likely corresponds to the first eluted peak in the RPLC chromatogram, which exists in the higher proportion. Therefore, we can likely assign the pseudo-doublet at $1.58 \mathrm{ppm}$ to the $s$-cis conformer. 


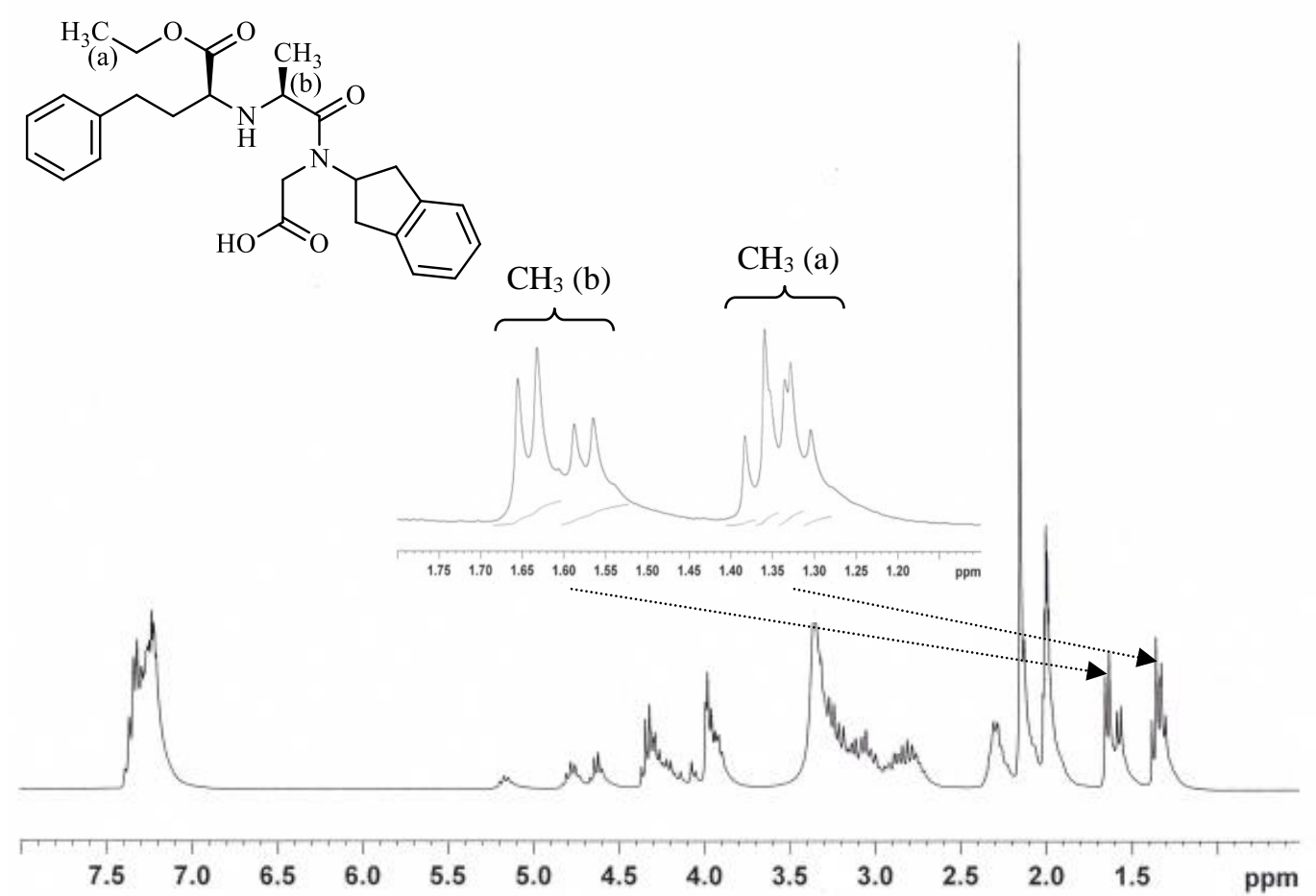

Figure 13. ${ }^{1} \mathrm{H}$ NMR spectrum of delapril in $\mathrm{CD}_{3} \mathrm{CN} / \mathrm{D}_{2} \mathrm{O}(9 / 1$, v/v) at $298 \mathrm{~K}$

The relative proportion of the two conformers at different temperatures in the range 298$328 \mathrm{~K}$ has been measured by relative integrals of the resonance signals of methyl group (b) of the two conformers of delapril present in the solution.
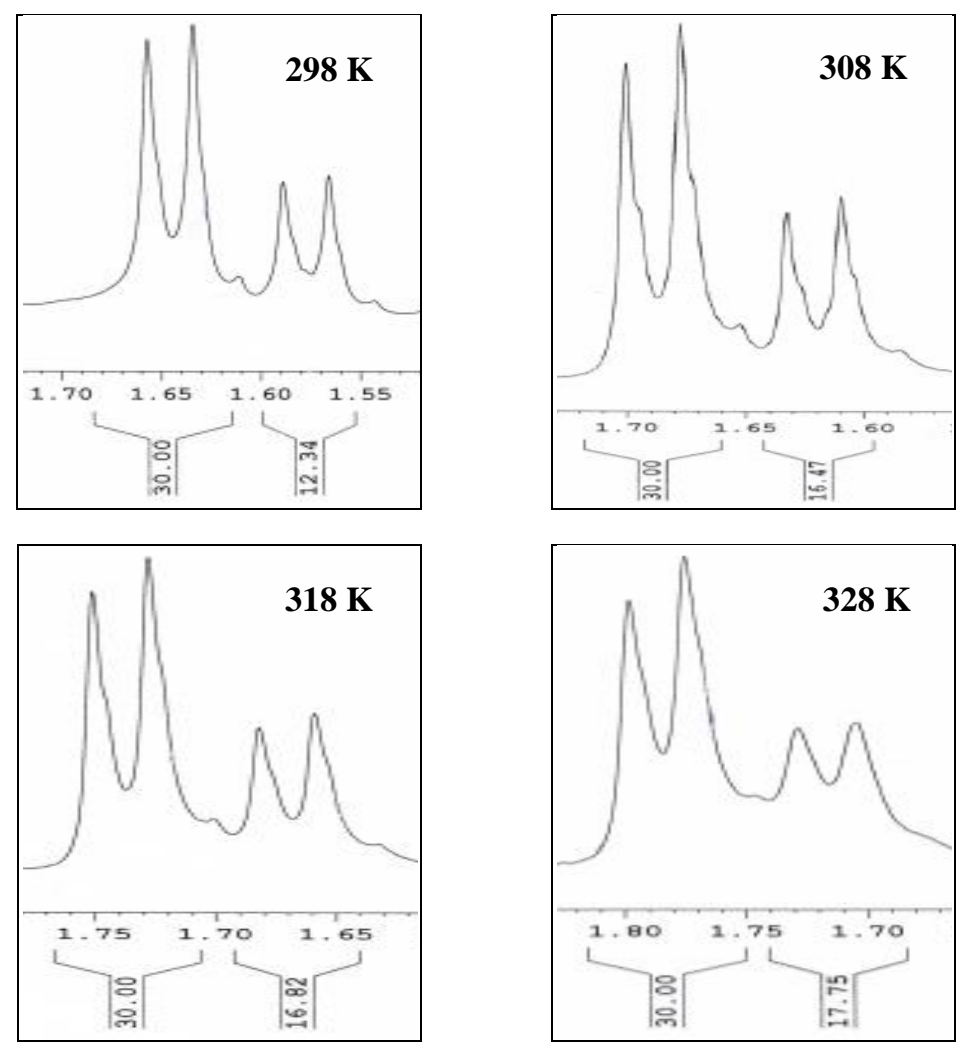

Figure 14. Effect of temperature on the relative proportion of the two conformers 
As shown in Figure 14, an increase of the temperature resulted in a moderate increase of the relative proportion of the minor isomer. These results suggest that the major conformer is the trans form and the minor conformer is the cis form, which is in agreement with measurements by E. Redenti et al. of delapril hydrochloride in DMSO-d ${ }^{6}$ at $294 \mathrm{~K}^{1}$.

\section{Conclusion}

The resolution and migration behavior of delapril are greatly influenced by operating conditions. It was demonstrated that rotamer separation can be achieved at ambient temperature by using appropriate concentration of organic solvent or the addition of a positively charged counter-ion. However, by choosing appropriate conditions delapril can also be eluted as a single peak. The proposed HPLC method is simple, specific, precise and accurate for the determination of delapril and can be reliably adopted for routine quality control analysis of delapril in its tablet dosage forms. The first-eluting isomer of delapril in the chromatographic system was assigned to be the trans-isomer, based on the characterization of equilibrated solutions of delapril in DMSO and in $\mathrm{CD}_{3} \mathrm{CN} / \mathrm{D}_{2} \mathrm{O}$ by NMR studies.

\section{References}

1 - E. Redenti, M. Zanol, G. Amari, P. Ventura, G. Fronza, A. Bacchi and G. Pelizzi, Il Farmaco, 1998, 53, 214-223.

2 - R. Razzetti and D. Acerbi, American Journal of Cardiology, 1995, 75, 7F-12F.

3- V. Todeschini, M. S. Sangoi and N. M. Volpato, European Journal of Mass Spectrometry, 2011, 17, 3, 287-296.

4- V. Todeschini, A. S. Meira, M. S. Sangoi, A. B. Barth, C. S. Paim and N. M. Volpato, Journal of Liquid Chromatography and Related Technologies, 2012, 35, 5, 603-620.

5 - V. Todeschini, A. T. Barden, L. L. Sfair, M. S. Sangoi and N. M. Volpato, Acta Chimica Slovenica, 2013, 60, 2, 335-342.

6 - V. Todeschini and M. S. Sangoi, Journal of AOAC International, 2014, 97, 1, 114-120.

7 - V. Todeschini, P. R. de Oliveira, L. S. Bernardi, R. L. Pereira, C. E. M. de Campos, M. A. S. Silva and N. M. Volpato, Journal of Thermal Analysis and Calorimetry, 2014, 115, 2295-2301.

8 - P. J. Rudzki, K. Buś, H. Ksycińska, and K. Kobylińska, Journal of Pharmaceutical and Biomedical Analysis, 2007, 44, 356-367.

9 - O. Trapp, G. Schoetz, and V. Schurig, Chirality, 2001, 13, 403-417.

10 - A. Ben Amar, M. Abidi, and N. Ben Hamida, Journal de la Société Chimique de Tunisie, 2013, 15, 9-17.

11 - D. Perrett and P. L. Drury, Journal of Liquid Chromatography, 1982, 5, 97-110.

12 - T. Kato, Analytica Chimica Acta, 1985, 175, 339-344.

13 - S. Gustafsson, B. M. Eriksson, and I. Nilsson, Journal of Chromatography, 1990, 506, 75-83.

14 - J. Salamoun and K. Slais, Journal of Chromatography, 1991, 537, 249-264.

15 - R. Bhushan and D. Gupta, Journal of Chromatography B, 2006, 837, 133-137.

16- T. Nishikawa, Y. Hayashi, S. Suzuki, H. Kubo, and H. Ohtani, Analytical Sciences, 1996, $12,561-564$.

17 - A. S. Rathore, and C. Horváth, Journal of Chromatography A, 1997, 787, 1-12. 
18 - R. Ledger and E. Stellwagen, Journal of Pharmacy and Pharmacology, 2005, 57, 845850.

19 - R. Cirilli, C. Di Bugno, and F. La Torre, Chromatographia, 1999, 49, 628-634.

20 - H. Trabelsi, S. Bouabdallah, S. Sabbah, F. Raoufi, and K. Bouzouita, Journal of Chromatography, 2000, 871, 189-199.

21 - S. Bouabdallah, H. Trabelsi, K. Bouzouita, and S. Sabbah, Journal of Biochemical and Biophysical Methods, 2002, 54, 391-405.

22 - S. Bouabdallah, H. Trabelsi, T. Ben Dhia, S. Sabbah, K. Bouzouita, and R. Khaddar, Journal of Pharmaceutical and Biomedical Analysis, 2003, 31, 731-741.

23 - S. Bouabdallah, H. Trabelsi, M. T. Ben Dhia, and N. Ben Hamida, Chromatographia, 2012, 75, 1247-1255.

24 - S. Bouabdallah, M. T. Ben Dhia, and M. R. Driss, International Journal of Analytical Chemistry, 2014, 1-8.

25 - S. Gebauer, S. Friebe, G. Scherer, G. Gübitz, and G-J. Krauss, Journal of Chromatographic Science, 1998, 36, 388-394.

26 - S. Gikas, F. Tsopelas, C. Giaginis, J. Dimitrakopoulos, T. Livadara, H. Archontaki, and A. Tsantili-Kakoulidou, Journal of Pharmaceutical and Biomedical Analysis, 2008, 48, 739-743.

27 - N. Tanaka, H. Goodell, and B.L. Karger, Journal of Chromatography, 1978, 158, 233248.

28 - X-Z. Qin, J. DeMarco, and D. P. Ip, Journal of Chromatography, 1995, 707, 245-254.

29 - A. Kálmán, F. Thunecke, R. Schmidt, P. W. Schiller, and C. Horváth, 1996, 729, 155171.

30 - medicine.cug.net/drug/05/05_03_02.htm.

31- United States Pharmacopeia, 29th Edition. United States Pharmacopeial Convention, Inc, Twinbrook Parkway, Rockville, MD, USA. pp. 1623, 2675-2693, 3050-3053, 33923394, 2006.

32 - US Food and Drug Administration, Center for Drug Evaluation and Research, Guidance for Industry: Analytical Procedures and Methods Validation. Chemistry, Manufacturing, and Controls Documentation DRAFT GUIDANCE, Rockville, MD, 2000. http://www.fda.gov/CDER/GUIDANCE/2396dft.pdf.

33 - International Conference on Harmonization (ICH) of Technical Requirements for the registration of Pharmaceuticals for Human Use, Guideline for Industry Q2A. Text on Validation of Analytical Procedures, Geneva: 1995. http://www.fda.gov/cder/Guidance/ichq2a.pdf. 